\title{
Ultrastructural changes of the egg apparatus associated with fertilisation of natural tetraploid Trifolium pratense L. (Fabaceae)
}

\author{
H. NURHAN BAKAR BUYUKKARTAL ${ }^{1}$
}

${ }^{1}$ Department of Biology, Faculty of Science, Ankara University, Ankara 06100, Turkey, bkartal@science.ankara.edu.tr

\begin{abstract}
The aim of this study is to describe the ultrastructural changes of the egg apparatus associated with fertilisation of the natural tetraploid Trifolium pratense. The pollen tube enters one of the synergids through the filliform apparatus from the micropyle. Before the entry of the pollen tube into the embryo sac, one of the synergids begins to degenerate, as indicated by increased electron density and a loss of volume. This cell serves as the site of entry for the pollen tube. Following fertilization, the vacuolar organisation in the zygote changes; in addition to the large micropylar vacuole, there are several small vacuoles of varying size. Ribosomal concentration increases significantly after fertilisation. In T. pratense, ultrastructural changes between the egg cell and zygote stages are noticeable. Several marked changes occur in the egg cell because of fertilisation. The zygote cell contains ribosomes has many mitochondria, plastids, lipids, vacuoles. After fertilization, most of the food reserves are located in the integument in the form of starch. The zygote shows ultrastructural changes when compared to the egg cell and appears to be metabolically active.
\end{abstract}

Key terms: egg apparatus; fertilisation; Trifolium pratense L.

\section{INTRODUCTION}

Tetraploid Trifolium pratense is an economically important forage legume naturally grown in Turkey for its tetraploid characteristics and high protein capacity. Naturally occurring tetraploid $T$. pratense $(2 \mathrm{n}=4 \mathrm{x}=28)$ is generally superior to the diploid forms in yield, disease resistance and persistence (Taylor and Smith, 1979). A large number of seeds are required for natural tetraploid $T$. pratense to be grown in large areas, but there are problems with seed setting in this plant. Several authors have studied relationships of sterility of $T$. pratense ovules and seed production (Martin, 1914; Fedortschuk, 1944; Povilaitis and Boyes, 1960; Mackiewicz, 1965; Shimada, 1977; 1978a; 1978b; Visynyakova, 1989; Leduc, et al. 1990). In a previous study, we observed that megagametophyte was formed in $18 \%$ of ovules examined, and about $13.9 \%$ of the total number of ovules observed were fertilised, but seed was formed by only $5.8 \%$ of the ovules (Algan and Bakar, 1997a). Algan and Bakar (1990) reported that seed abortion might be due to several factors. There may be some problems in microspore and megaspore formation due to difficulties in male and female gametophyte or in the fertilization and postfertilisation stages. Female gametopyte development in the natural tetraploid $T$. pratense has been examined and some difficulties have been identified observed (Algan and Bakar, 1990). Besides, embryo and endosperm development (Algan and Bakar, 1996) and the ultrastructure of the megagametophyte were investigated in details (Algan and Bakar, 1997a). But there are no reports dealing with the fine structure of fertilisation in this plant. This paper extends our previously reported observations and describes the ultrastructural changes of

Corresponding Author: Department of Biology, Faculty of Science, Ankara University, Ankara 06100, Turkey, E-mail: bkartal@science.ankara.edu.tr 
the egg apparatus of the fertilised ovules in T. pratense.

\section{MATERIALS AND METHODS}

Plants of natural tetraploid $T$. pratense variety E2 derived from a plant having 28 chromosomes $(2 \mathrm{n}=4 \mathrm{x}=28$ determined by counting chromosomes at root tips) were grown under natural conditions. The aforementioned plants were collected from the Tortum Region in Erzurum (Turkey) by Elçi (1982). Ovaries were separated into various development stages according to ovary size. Selected ovules were excised and fixed in $3 \%$ glutaraldehyde in phosphate buffer at $\mathrm{pH} 7.3$ for $6 \mathrm{~h}$ at room temperature and post-fixed with $1 \%$ buffered osmium tetraoxide for $3 \mathrm{~h}$. After rinsing, the material was dehydrated in a graduated ethanol series and then embedded in Epon 812 (Luft, 1961). Ultra-thin sections were stained with uranyl acetate and lead citrate. In total about 225 ovules were analyzed. Ultrastructural observations were made using a JEOL 100 CXII transmission electron microscope at 80 $\mathrm{kV}$. Semi-thin sections were stained with 1 $\%$ methylene blue in distilled water and observed by LM.

\section{RESULTS AND DISCUSSION}

Prior to fertilization the egg apparatus consists of the egg cell and two synergids. The micropylar end of both synergids is occupied by the complex filiform apparatus (FA). In some of the ovules one of the two synergids had degenerated prior to the fertilisation of the egg cell (Figure 1). Before pollination, the two synergids are sister cells and no structural differences between the two cells can be seen. No ultrastructural changes occur in the persistent synergid as the other synergid degenerates; organelles remain numerous and structurally intact.

The chalazal part of the persistent synergid is occupied by a large vacuole and most of the cytoplasm is situated at the micropylar part of the cell. The cytoplasm has a rich complement of organelles, especially extensive rough endoplasmic reticulum (RER), dictyosomes, and abundant ribosomes, plastids, lipid bodies, and mitochondria (Figure 2). The cytoplasmic and nuclear fine structure of the synergids of $T$. pratense are shown by this study to be essentially similar to that of other species, but the behaviour of the synergids in a certain number of the ovules examined seems to be different from that found in other species. In some ovules of $T$. pratense, similar to most species studied so far, one synergid begins to degenerate just before the pollen tube enters into the embryo sac; in the others (that also contain a megagametophyte) synergid degeneration occurs soon after pollination. In $T$. pratense L., fertilisation is effected within 24 hours after pollination (Martin, 1914). In some of the examined ovules $(3.55 \%)$, the micropyle was filled with one pollen tube (Figure 3). Penetration by more than one pollen tube was observed. Degeneration of a nucellus cell close to the micropyle takes place in some ovules. When the pollen tube reaches the megagametophyte, it elongates several micrometers before discharging grows into the degenerating synergid through the filiform apparatus (Figure 4). The penetration and discharge of the pollen tube causes further degeneration of that synergid. The plasma membrane of the degenerating synergid disappears, the cytoplasm becomes dark, and osmiophilic, the large chalazal vacuole of this cell begins to fragment and most of its organelles, and membrane bodies are no longer visible (Figure 5). At this stage the degenerate synergid is filled with polysacharide vesicles, lipid bodies, mitochondria, and membrane remnants (Figure 6).

Degeneration of one of the two synergids during fertilisation is common in $T$. pratense and other angiosperms (Folsom and Cass, 1986; Dute et al. 1989; Sumner, 1992). The zygote increases in ribosome concentration, as well as number of lipid bodies and vacuole number and size. The zygote is elongated in size compared to the egg cell (Figures 7 - 8). The zygote has a length of from $17.8 \mu \mathrm{m}$ to $187.7 \mu \mathrm{m}$ and a width of from $13.3 \mu \mathrm{m}$ to $14.8 \mu \mathrm{m}$, but the egg cell has a length of from $13.0 \mu \mathrm{m}$ to $13.1 \mu \mathrm{m}$ and a width of from 12.4 

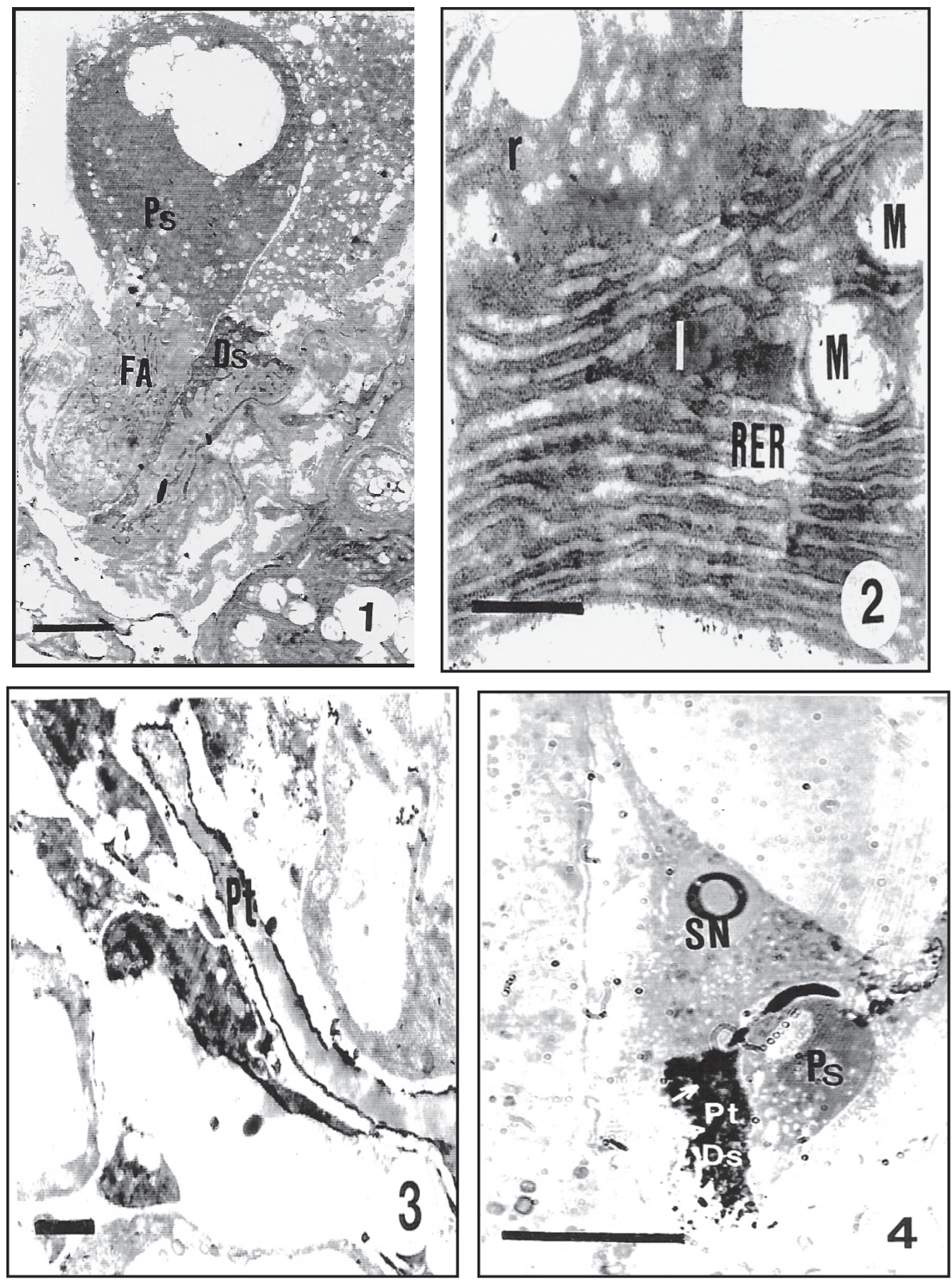

Figures 1-4: 1. Electron micrograph showing a longitudinal section of the degenerate synergid (DSY) and persistent synergid (PSY) cells. Micropylar region of both synergids showing the filliform apparatus $(\mathrm{FA})$. $(\mathrm{Bar}=10 \mu \mathrm{m})$ : 2. Electron micrograph of the persistent synergid cytoplasm showing the rough ER (RER), mitochondria (M), ribosomes (R), and lipid body (L) (Bar $=1 \mu \mathrm{m}): 3$. Electron micrograph of the micropylar region of megagametophyte observed one pollen tube $(\mathrm{PT})$ in the micropyle $(\mathrm{Bar}=3 \mu \mathrm{m})$ : 4 . Light micrograph of a semithin section showing pollen tube entry into megagametophyte. The pollen tube (PT) enters the degenerate synergid (DSY) via the FA. Note the pollen tube grows some distance before discharging into the degenerating synergid (arrows) $($ Bar $=20 \mu \mathrm{m})$. 

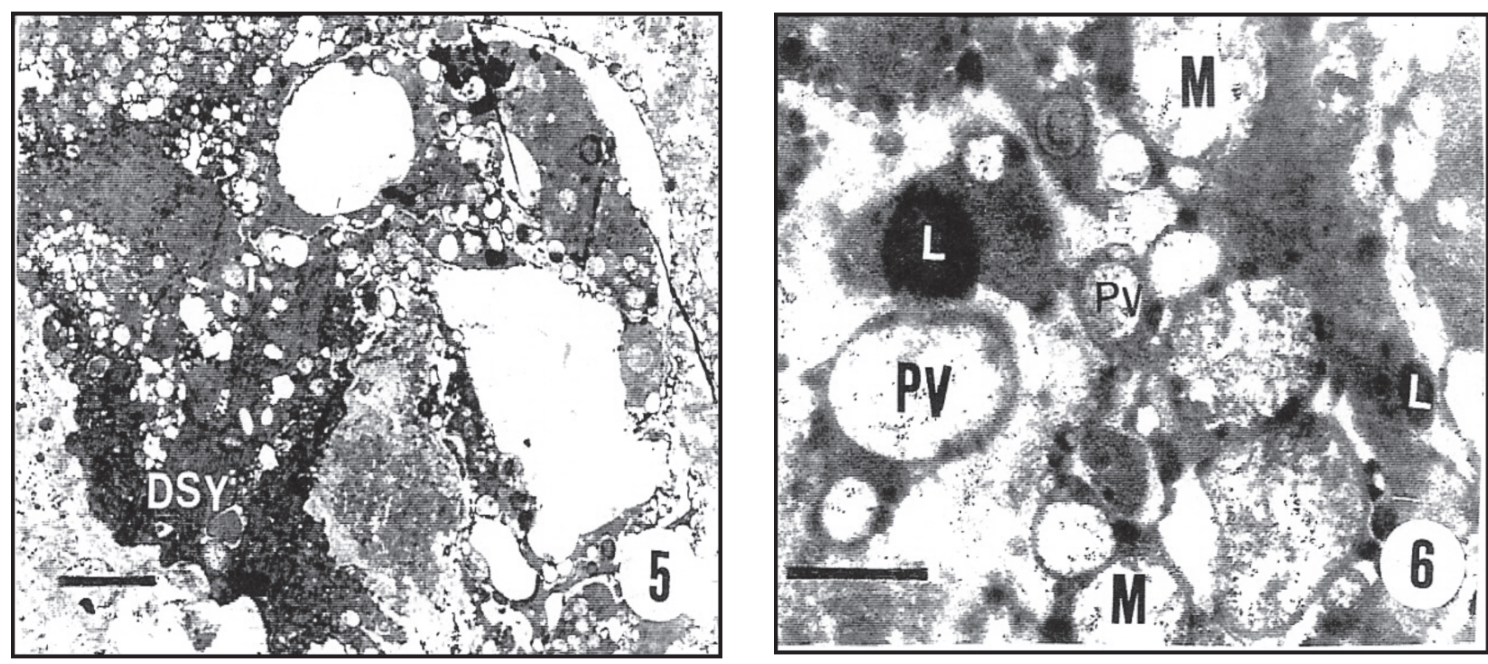

Figures 5-6: 5. Portion of the megagametophyte showing, the degenerating synergid (DSY). Note the masses of the dense material $(\mathrm{Bar}=1 \mu \mathrm{m})$ : 6 . The cytoplasm of the degenerated synergid cell, which contains lipid bodies (L), polysaccharide vesicles (PV), and mitochondria (M). (Bar = $1 \mu \mathrm{m})$.
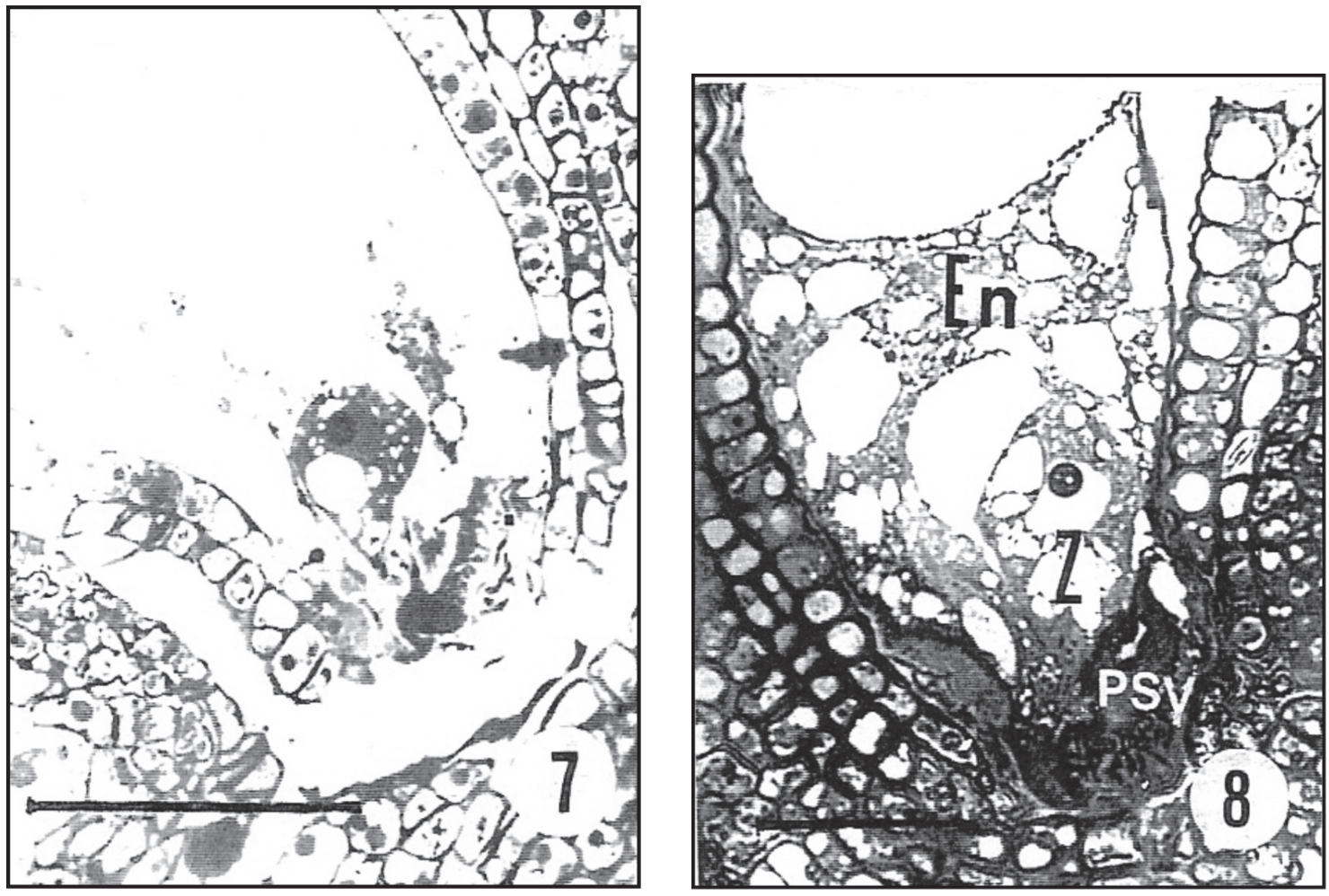

Figures 7-8: 7. Light micrograph of megagametophyte showing the mature egg cell $(\mathrm{Bar}=50 \mu \mathrm{m})$ : 8. Light micrograph of the egg cell after fertilisation. Note the zygote $(Z)$ has elongated and the persistent synergid (PSY) degenerates. En; Endosperm. (Bar $=50 \mu \mathrm{m})$. 
$\mu \mathrm{m}$ to $13.7 \mu \mathrm{m}$. In a small number of the examined ovule, the zygote nucleus was seen to be different shapes. The zygote nucleus is usually large and oval shaped, and has an electron dense nucleolus. In some ovules $(2.66 \%)$ the large micropylar vacuole found in the egg seems to fragment into smaller vacuoles. In its place, many small vacuoles were distributed throughout the zygote cytoplasm (Figure 9). The zygote cytoplasm contains numerous cup-shaped plastids, ribosomes, rough ER, lipid bodies, amyloplasts, and mitochondria (Figure 10). The mitochondria remain structurally simplified at this stage (Figure 11). Many of the mitochondria are concentrated in the micropylar region of the zygote cytoplasm. Amyloplasts of varied shapes often contain large starch grains which seem more numerous, and highly developed in the zygote than in the egg. Occasional small protein bodies are seen in the cytoplasm. ER and
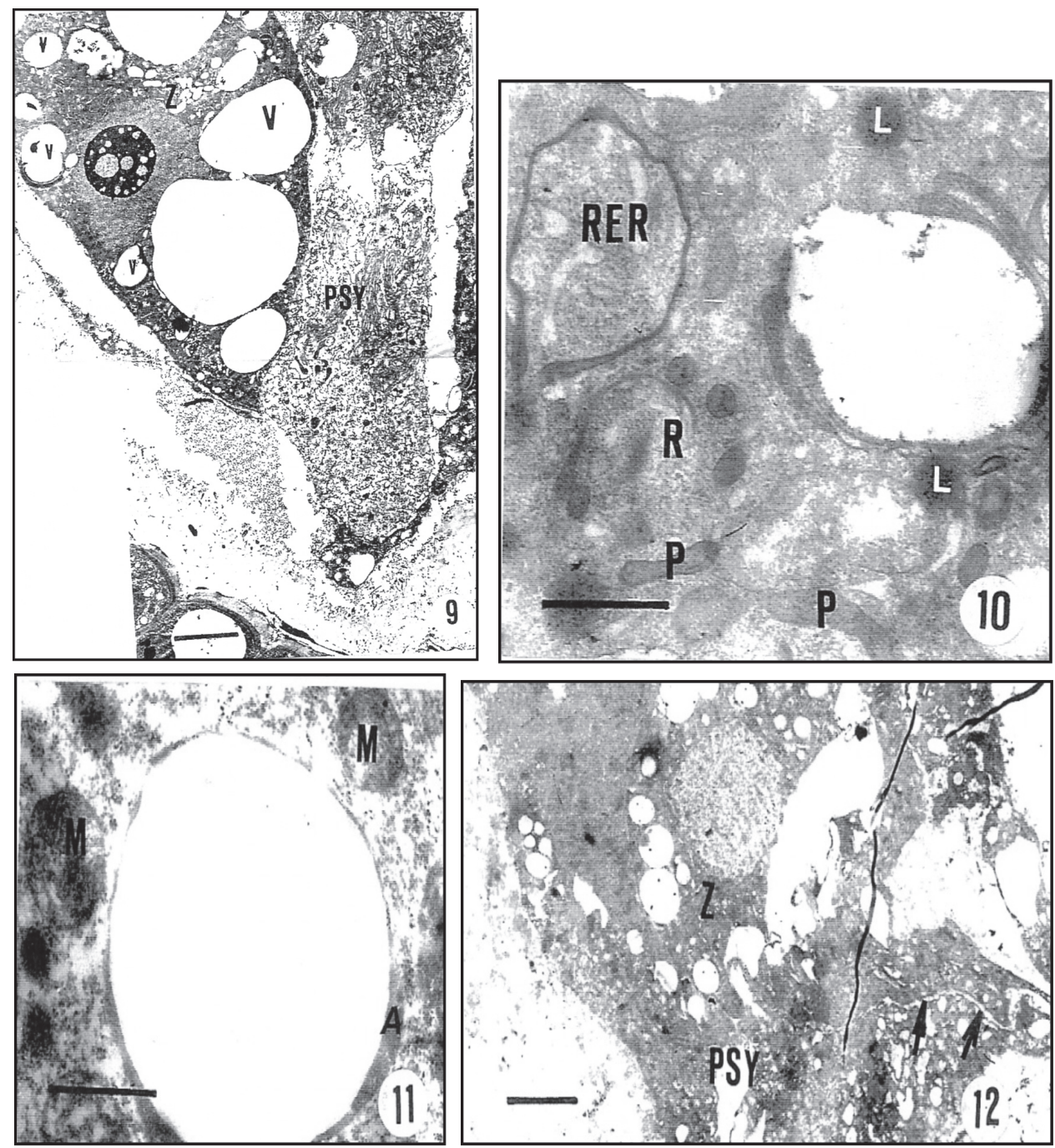

Figures 9-12: 9- Electron micrograph of the fertilised megagametophyte showing the zygote (Z) and persistent synergid (PSY). Note the zygote has elongated and contains a number of vacuoles (V) $($ Bar $=1 \mu \mathrm{m})$ : 10- Portion of the zygote cytoplasm which contains ribosomes (R), rough ER (RER), lipid bodies $(\mathrm{L})$, and plastids $(\mathrm{P})(\mathrm{Bar}=2 \mu \mathrm{m})$ : 11 - Detail of the zygote cytoplasm showing numerous mitochondria $(\mathrm{M})$, and large starch containing amyloplast $(\mathrm{A})$. (Bar $=1 \mu \mathrm{m})$ : 12- Zygote (Z) and degeneration of the persistent synergid (PSY). Note the zygote is separated from the degenerate synergid by a thin cell wall (arrows) $($ Bar $=1 \mu \mathrm{m})$. 
dictyosomes are rare in the cytoplasm. In $T$. pratense ultrastructural changes between the egg cell and zygote stages are noticeable. Several marked changes occur in the egg cell because of fertilisation. The zygote cell contains ribosomes, many mitochondria, plastids, lipids, and vacuoles. The presence of starch grains and lipid bodies suggests some food storage for the energy needed during the early stage of zygote development. After fertilisation most of the food reserves are located in the integument in the form of starch (Bakar and Algan, 1997b; Algan and Bakar, 2000). The zygote shows position dependent differences in cell walls formed in different regions of the cell. The zygote attaches to the micropylar wall of megagametophyte and is separated from the degenerate synergid by a thin wall (Figure 12).

Ultrastructural differences between the egg cell and zygote have been observed in many species. Reduction in the size of the egg cell following fertilisation occurs in sunflower (Sumner, 1992). An increase in the number of the cytoplasmic organelles and stored products in the zygote has been reported in Capsella (Schulz and Jensen, 1968) and sunflower (Sumnner, 1992). In addition, complete formation of the egg cell wall after fertilisation has been observed in Quercus (Singh and Mogensen, 1975). Approximately $18 \%$ of the Trifolium pratense $\mathrm{L}$. ovules examined contained a normal megagametophyte, but seed formation was only $5.8 \%$. Thus, the rate of seed set was lower than the formation of the megagametophyte.

Fertilisation occurs in a relatively small numbers of the ovules $(13.9 \%)$. These data show that ovule abortion is occuring in fertilised ovules. Many different causes seem to be involved in the ovule abortions. Additional cytological examinations are needed to understand causes of female sterility.

\section{REFERENCES}

ALGAN G, BAKAR HN (1990) The study of the development of embryo sac and formation of egg in the natural tetraploid red clover (Trifolium pratense L). Doga Turk J. Bot. 15: 57-70
ALGAN G, BAKAR HN (1996) Light and electron microscopic examination of the embryo and endosperm development in the natural tetraploid Trifolium pratense L. Isr. J. Pl. Sci. 44: 273-288

ALGAN G, BAKAR HN (1997a) The ultrastructure of the mature embryo sac in the natural tetraploid red clover (Trifolium pratense L.) that has a very low rate of seed formation. Acta Soc. Bot. Pol. 66: 13-20

BAKAR HN, ALGAN G (1997b) Electron microscopic examination of the development of the endothelium in Trifolium pratense L. during development. Doğa Turk. J. Bot. $21: 137-144$

ALGAN G, BAKAR BUYUKKARTAL HN (2000) Ultrastructure of seed coat development in the natural tetraploid Trifolium pratense L. J. Agr. and Crop Sci. 183: 205-213

DUTE RR, PETERSON CM, RUSHING AE 1989 ultrastructural changes of the egg apparatus associated with fertilization and proembryo development of soybean, Glycine max (Fabaceae). Ann. Bot. 644: 123135

ELÇI Ş (1982) The utilization of genetic resource in fodder crop breeding. Eucarpia Fodder Crop Section, 13-16 September, Aberystwyth UK

FEDORTSCHUK VF (1944) Development and structure of ovules and seeds in red clover (Trifolium pratense L.). Moscow State publ. Agr. Litt. 25: 1-39

FOLSOM MW, CASS DD (1986) Changes in transfer cell distribution in the ovule of Soybean after fertilization. Can. J. Bot. 64: 965-972

LEDUC N, DOUGLAS GC, MONMER M, CONNOLLY DV (1990) Pollination in vitro; effects on the growth of pollen tubes, seed set and gametophytic self incompatibility in Trifolium pratense L. and Trifolium repens L. Theor. Appl. Genet. 80: 657-664

LUFT JH (1961) Improvements in epoxy resin embedding methods. J. Biophys. Cytol. 9: 409-414

MACKIEWICZ T (1965) Low seed setting in tetraploid red clover (Trifolium pratense L.) in the light of cytoembryological analysis. Genet. Pol. 11: 241-247

MARTIN JN (1914) Comparative morphology of some Leguminosae. Bot. Gaz. 58: 154-167

POVILAITIS B, BOYES JW (1960) Ovule development in diploid red clover. Can. J. Bot. 38: 507-532

SCHULZ SR, JENSEN WA (1968) Capsella embryogenesis: the egg, zygote and young embryo. Am. J. Bot. 55: 807-819

SHIMADA T (1977) Occurence of sterility in tetraploid red clover 3: Cytological aspects of sterility. Res. Bull.Obihiro Univ. Series 110: 737-742

SHIMADA T (1978a) Occurence of sterility in tetraploid red clover 4. Embryology of sterility in diplo id and tetraploid plants. Res. Bull.Obihiro Univ. Series 110: 815-827

SHIMADA T (1978b) Occurence of sterility in tetraploid red clover 5. Embryo logical aspects of sterility. Res. Bull.Obihiro Univ. Series 110: 829-835

SING AP MOGENSEN HL (1975) Fine structure of the zygote and early embryo in quercus gambelii. Am. J. Bot. 62: 105-115

SUMNER MJ (1992) Embryology of Brassica campestris : the entrance and discharge of the pollen tube in the synergid and the formation of zygote. Can. J. Bot. 70: $1577-1590$

TAYLOR NL, SMDTH RR (1979) Red clover breeding and genetics. Adv. Agr. 31: 125-154

VISYNYAKOVA MA (1989) Study of the progamic phase of fertilization in red clover $\{$ Trifolium pratense L.) in relation to low seed production. Sbornik Nauc. Trud. Prıkladnoi bot.,Genetike-i-Seleksi 124: 7-14 